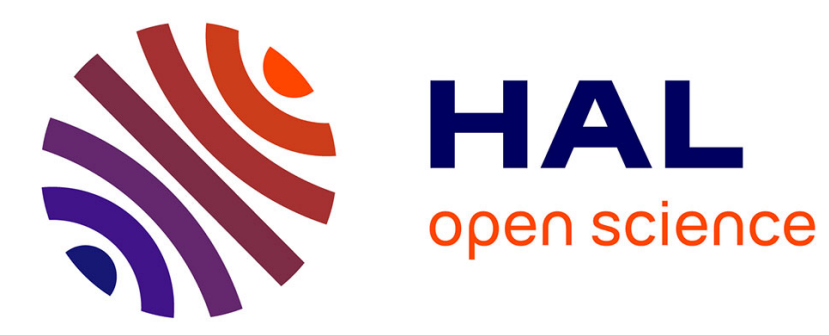

\title{
High temperature oxidation behaviour of laser surface alloyed iron-silicon coatings on iron
}

\author{
Sylvaine Roy, A. Fasasi, M. Pons, A. Galerie, M. Caillet
}

\section{To cite this version:}

Sylvaine Roy, A. Fasasi, M. Pons, A. Galerie, M. Caillet. High temperature oxidation behaviour of laser surface alloyed iron-silicon coatings on iron. Journal de Physique IV Proceedings, 1993, 03 (C9), pp.C9-625-C9-633. 10.1051/jp4:1993966 . jpa-00252406

\section{HAL Id: jpa-00252406 https://hal.science/jpa-00252406}

Submitted on 1 Jan 1993

HAL is a multi-disciplinary open access archive for the deposit and dissemination of scientific research documents, whether they are published or not. The documents may come from teaching and research institutions in France or abroad, or from public or private research centers.
L'archive ouverte pluridisciplinaire HAL, est destinée au dépôt et à la diffusion de documents scientifiques de niveau recherche, publiés ou non, émanant des établissements d'enseignement et de recherche français ou étrangers, des laboratoires publics ou privés. 


\title{
High temperature oxidation behaviour of laser surface alloyed iron-silicon coatings on iron
}

\author{
S.K. Roy, A. Fasasi, M. Pons, A. Galerie and M. Caillet \\ Laboratoire Science des Surfaces et Matériaux Carbonés, URA CNRS n ${ }^{\circ} 413$, ENS d'Electro- \\ chimie et d'Electrométallurgie de Grenoble, Institut National Polytechnique de Grenoble, B.P. 75, \\ Domaine Universitaire, 38402 Saint-Martin d'Hères, France
}

\begin{abstract}
Iron silicide ( $\mathrm{Fe}_{3} \mathrm{Si}$ ) coatings of composition $\mathrm{Fe}-16$ at\% $\mathrm{Si}$ and $\mathrm{Fe}-25$ at\% $\mathrm{Si}$ have been produced by laser surface alloying on pure iron substrates with predeposited silicon powder. The coatings showed excellent adherence without any pores or cracks. They were compositionally and microstructuraly homogeneous, exhibiting two to three times higher surface hardness values than pure iron. High temperature oxidation resistance of the coatings were tested in the temperature range $1173-1273 \mathrm{~K}$ in static pure oxygen $\left(P_{\mathrm{O}_{2}}=13.3 \mathrm{kPa}\right)$. Their superiority compared to bulk alloys and CVD coatings is discussed.
\end{abstract}

\section{Introduction.}

High temperature alloys are expected to serve in a demanding atmosphere by maintaining their physical integrity which is imparted to them by addition of specific alloying elements. However, in the development of such alloys, it has always been encountered that good strength property is obtained only at the expense of oxidation resistance for which many of the presently used alloys need to be coated for satisfactory services under an agressive atmosphere. Protective coatings in oxidizing atmospheres are broadly classified into three main groups, depending on the type of protective scales they form: a) alumina formers; b) chromia formers and c) silica formers. There have been many investigations on the development of $\mathrm{Cr}_{2} \mathrm{O}_{3}$ and $\mathrm{Al}_{3} \mathrm{O}_{3}$ scales. However, studies relating to the development of the third protective scale, i.e. $\mathrm{SiO}_{2}$, have been very few and as such, comparatively little is known about its mode of formation and growth.

Additions of suitable amount of silicon to the bulk of wrought and cast iron-base alloys have been found to increase surface properties like, resistance to oxidation [1-6], sulfidation [5] and carburization [7] at high temperatures as well as to corrosion in aqueous inorganic acids [8]. But silicon being a ferrite stabilizer, its addition in large amount impairs the desirable mechanical properties, particularly strength and ductility, for which most of the earlier studies $[1-4,6]$ were confined to 10 at\% $\mathrm{Si}$. Now, if the alloying addition could be confined only to the surface of the alloy by adopting surface modification technologies like reactive CVD [9], pack cementation [10] or laser surface alloying [11-13], improved surface properties could be achieved without affecting the bulk properties.

Laser surface alloying provides an unique opportunity where, with ease, rapidity and cleanliness, very high rate of energy delivery facilitates localized surface melting of the predeposited alloying element and a portion of the substrate to form controllable microstructures. 
This paper describes the preparation and characterization of $\mathrm{Fe}-\mathrm{Si}$ surface alloys as coatings produced by irradiation of varying quantities of predeposited silicon powders on iron substrates for which no reporting exists in the literature. Further, the morphologies of the surface alloys so formed, their microhardness characteristics and high temperature oxidation behaviour are reported.

\section{Experimental procedure.}

Silicon powders $(d \sim 160 \mu \mathrm{m})$ suspended in ethanol were uniformly deposited by spraying on the degreased surfaces of pure iron (supplied by M/S Goodfellows Metals Ltd having a purity of $99.5 \%$ with principal impurities as $\mathrm{Si}$, $\mathrm{Mn}$ and $\mathrm{C}$ ) blocks of dimensions $20 \times 15 \times 1.5 \mathrm{~mm}$ and left to dry in air. The two different quantities of silicon deposited corresponded to an area coverage of 4 and $9 \mathrm{mg} \cdot \mathrm{cm}^{-2}$ and this resulted in predeposit thickness of 17 and $40 \mu \mathrm{m}$ respectively. Irradiations, which were performed under argon gas shield to prevent premature oxidation, were done with a continuous wave Nd:YAG laser having a maximum attainable power of 300 Watts and guided by an optical fibre to produce a spot diameter of $\sim 950 \mu \mathrm{m}$. The computer controlled $x-y$ translation stage has a maximum theoretical scanning speed of $40 \mathrm{~mm} \cdot \mathrm{s}^{-1}$ with a linear resolution of $1 \mu \mathrm{m}$. All the six faces of each specimen were irradiated.

The power and the scanning speed were varied systematically in order to obtain the optimum operating parameters for the formation of well adherent, defect free and compositionally homogeneous surface alloy coatings. The surfaces of a pure iron sample without any predeposit were also irradiated to serve as a reference. The surface alloys so formed were characterized by optical microscopy, XRD, SEM, EDS and EPMA. The microhardness of the alloys at their surfaces as well as along the transverse section of the melt depths were measured with a Buehler microhardness tester at a constant load of $100 \mathrm{gf}$. High temperature oxidation kinetics of the coatings were studied at temperatures between 1173 and $1273 \mathrm{~K}$ in pure oxygen at a constant static pressure of $13.3 \mathrm{kPa}$ (100 torr) for time ranging from 50 to 140 hours. The weight changes of the specimens were recorded continuously using a Setaram-B70 microbalance with an accuracy of $50 \mu \mathrm{g}$. For simplicity sake, the flat surface areas of the specimens have been considered in calculating the weight gain per unit area. Post oxidation analysis of the scale-alloy combination have been carried out with XRD, SEM and EPMA.

\section{Results and discussion.}

Preliminary studies established that it was necessary to adopt the following laser operating conditions to obtain defect-free, compositionally and microstructurally homogeneous alloys:

$$
\begin{array}{llll}
\text { power }(P) & =150 \mathrm{~W}, & \text { power density }\left(q_{0}\right) & =1.02 \times 10^{8} \mathrm{~W} \cdot \mathrm{m}^{-2} \\
\text { scanning speed }(V) & =4 \mathrm{~mm} \cdot \mathrm{s}^{-1}, & \text { area coverage }\left(A_{\mathrm{c}}\right) & =4 \text { and } 9 \mathrm{mg} \cdot \mathrm{cm}^{-2} \\
\text { overlapping } & =50 \%, & \text { protective gas ran } & =\operatorname{argon}(\text { flow rate of } \\
& & & \left.5.01 \cdot \mathrm{min}^{-1}\right) .
\end{array}
$$

$\mathrm{X}$-ray analyses of the two surface alloys detected the presence of $(\alpha)-\mathrm{Fe}_{3} \mathrm{Si}$. The surfaces of the laser treated samples were very bright with ripples. The two surfaces produced from 


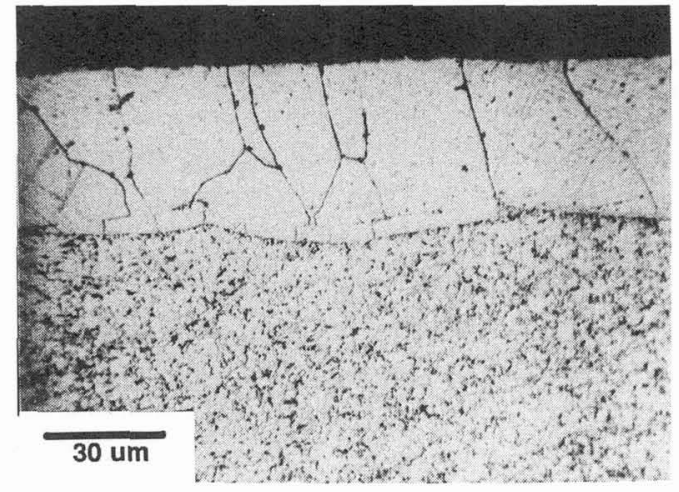

Fig. 1. - Typical microstructure of a Fe-Si alloy after surface alloying by laser irradiation. Condition of elaboration: $P=150 \mathrm{~W} ; V=4 \mathrm{~mm} \cdot \mathrm{s}^{-1} ; A_{\mathrm{c}}=4 \mathrm{mg} \cdot \mathrm{cm}^{-2}$.

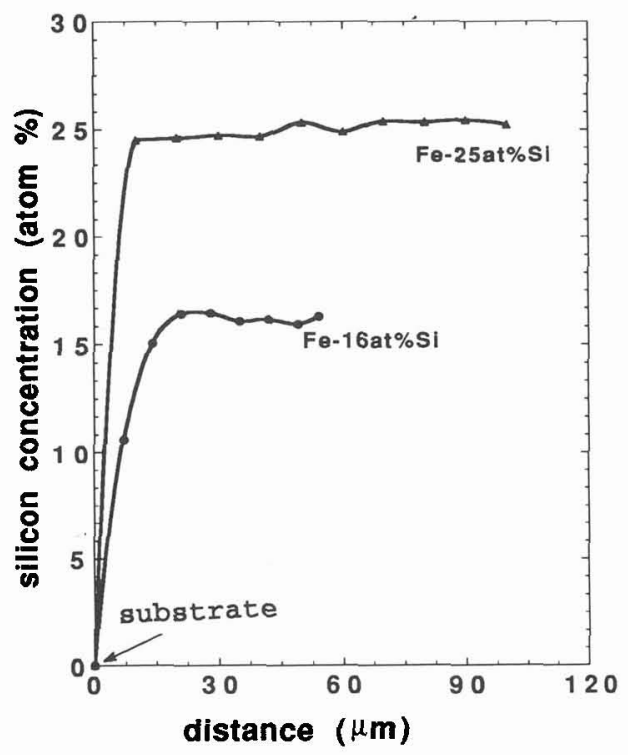

Fig. 2. - The concentration profiles of silicon in $\mathrm{Fe}-16$ at\% Si and Fe-25 at\% Si surface alloys after laser irradiation.

the two different amounts of predeposited silicon exhibited identical microstructures. A representative optical micrograph of the cross section of the surface alloy is shown in figure 1 , which depicts an initial narrow plane front solidification with high nucleation rate at the alloy/substrate interface, followed by large columnar grains extending up to the surface of the alloy. The elemental analyses carried out by EPMA and reproduced in figure 2 revealed the amount of silicon in the two alloys to be 16 and 25 at\% with melt depths of 54 and $100 \mu \mathrm{m}$ for predeposited silicon of 4 and $9 \mathrm{mg} \cdot \mathrm{cm}^{-2}$ respectively. The increase in the melt depth for the higher quantity of predeposited silicon under identical conditions of laser irradiation is 
probably due to higher thermal conductivity of silicon. As a consequence the silicon content of the surface alloy is not largely affected by the quantity of predeposited silicon.

The microhardness values measured along the cross-section in the center of the pass of the two surface alloys are shown in figure 3 which clearly demonstrates the beneficial effect of higher silicon content. For the two alloys the hardness was highest on the surface (500 and $640 \mathrm{HV}_{0.1}$ for Fe-16 at\% Si and Fe-25 at\% Si respectively), with a slight drop in the alloyed zone followed by a gradual decrease in the heat affected zone until the substrate is reached, where the lowest value of $140 \mathrm{HV}_{0.1}$ was recorded.

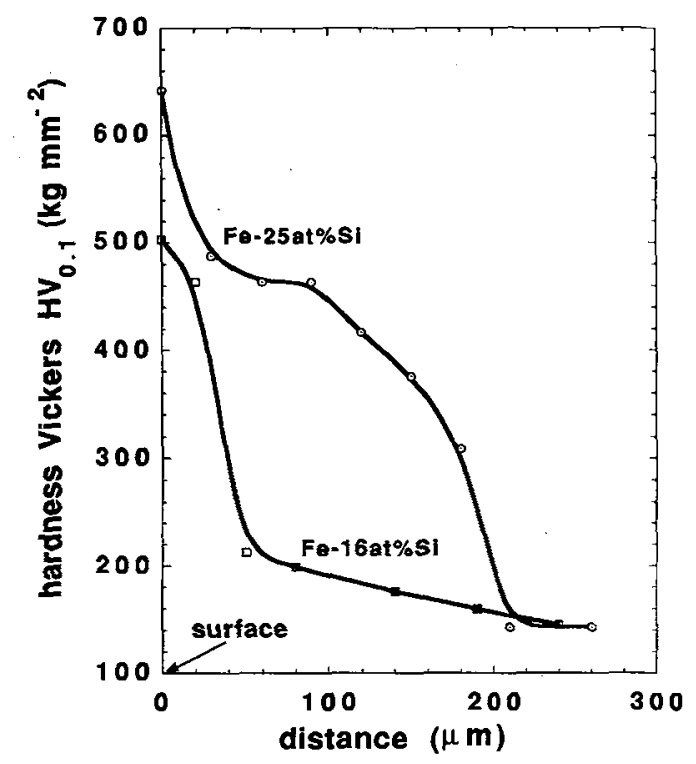

Fig. 3. - Variation of Vickers hardness along the centre of a laser pass from alloy surface to substrate for $\mathrm{Fe}-16$ at\% $\mathrm{Si}$ and $\mathrm{Fe}-25$ at\% Si alloys.

In laser surface alloying with multiple passes, one may encounter microstructural difference between the center and the overlapped regions of the passes. This microstructural difference, which is due originally to the convective flow field and the degree of overlapping, was also characterized by hardness measurements. Figure 4 shows the measured hardness data between three successive overlapped regions along the direction of the laser pass at a depth of about $20 \mu \mathrm{m}$ below the top surface. Both of the alloys exhibited identical characteristics: the highest values being recorded in the overlapped regions with a gradual decrease towards the center of the pass. Similar behaviour was also observed for stainless steel [14] simply on irradiation without any alloy additions.

The oxidation kinetics of laser melted pure iron and those of the two surface alloys are represented in figures 5 and 6 . The surface alloys showed paralinear behaviour with a brief parabolic characteristic during the early period of oxidation as shown in the inset of figure 5 . The direct comparison of the absolute values of the weight gain data of the present study with those reported for bulk alloys [5] and surface alloys produced by reactive CVD [9] in the similar compositional range, is not justified because, with laser treatment, much larger 


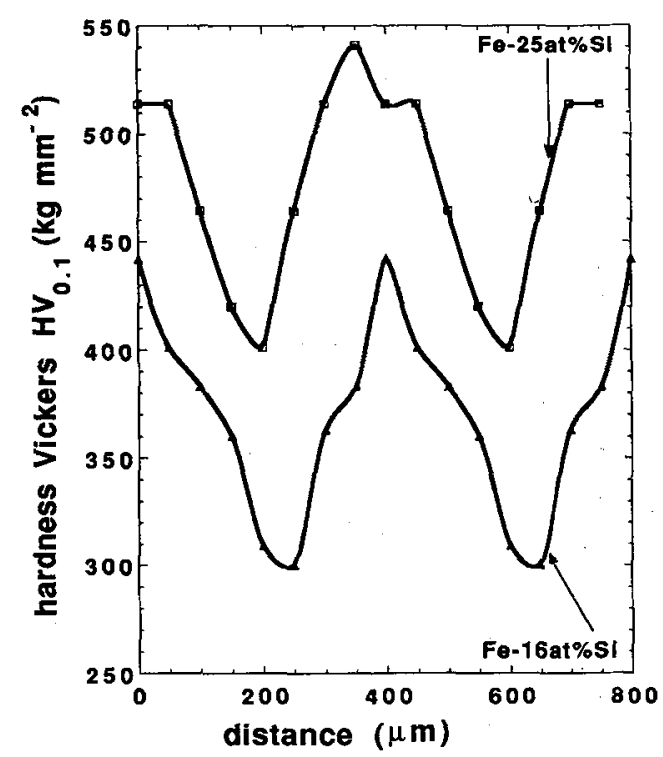

Fig. 4. - Influence of overlapping on hardness. Measurements were taken at about $20 \mu \mathrm{m}$ below the surfaces of $\mathrm{Fe}-16$ at $\% \mathrm{Si}$ and $\mathrm{Fe}-25$ at\% Si surface alloys.

surface area is generated due to ripple formation. Therefore, the given curves, not taking into account this phenomenon, are to be considered as the most pessimistic. In spite of that, the beneficial effect of laser surface alloying of silicon with iron in reducing the oxidation rate is well demonstrated and the kinetic behaviour is almost identical to that reported by others $[5,9]$.

$\mathrm{X}$-ray analyses of the resultant scale on pure iron showed the presence of $\mathrm{FeO}, \mathrm{Fe}_{3} \mathrm{O}_{4}$ and $\mathrm{Fe}_{2} \mathrm{O}_{3}$, while for both of the surface alloys, only $\mathrm{Fe}_{2} \mathrm{O}_{3}$ was detected at all temperatures of investigation. The scales formed on both of the alloys were adherent, compact and highly tenacious with no evidence of spallation on cooling. However, at some isolated areas (2-5\% of the total surface area), nodules appeared.

SEM observations of the top surface of the scale on pure iron revealed large grains of $\mathrm{Fe}_{3} \mathrm{O}_{4}$ with $\mathrm{Fe}_{2} \mathrm{O}_{3}$ mainly along the grain boundaries. The cross-section of the scale exibited three consecutive oxide layers which are usually observed on oxidation of pure iron i.e., a thin external layer of $\mathrm{Fe}_{2} \mathrm{O}_{3}$, a middle layer of $\mathrm{Fe}_{3} \mathrm{O}_{4}$ and an inner layer of $\mathrm{FeO}$ containing fine precipitates of $\mathrm{Fe}_{3} \mathrm{O}_{4}$. A typical cross-section of the scale developed on Fe-16 at\% Si observed by SEM is shown in figure 7 . This figure shows a duplex structure consisting of $\mathrm{SiO}_{2}$ and $\mathrm{Fe}_{2} \mathrm{O}_{3}$ at the scale base surmounted by an external layer of $\mathrm{Fe}_{2} \mathrm{O}_{3}$ only. No internal oxidation was detected in the subjacent alloy, but elemental analyses confirmed the inward diffusion of silicon into the substrate.

At the alloy/scale interface, the concentration of silicon did not ever fall below 6 at $\%$. The $\mathrm{X}$-ray map of silicon in the oxide scale is reproduced in figure 8 which shows the presence of discontinuous $\mathrm{SiO}_{2}$ layer at the base of the outer $\mathrm{Fe}_{2} \mathrm{O}_{3}$ layer. The concentration of silicon increased near the base of the duplex scale where $\mathrm{FeO}_{3}$ and $\mathrm{SiO}_{2}$ were interspersed making it smoother. The exact nature of $\mathrm{SiO}_{2}$ formed in alloy oxidation had always remained a subject of controversy. Earlier works on Fe-Si [3], Ni-Si [15], Cu-Si [16, 17] and Ni-Cr-Si [18] 


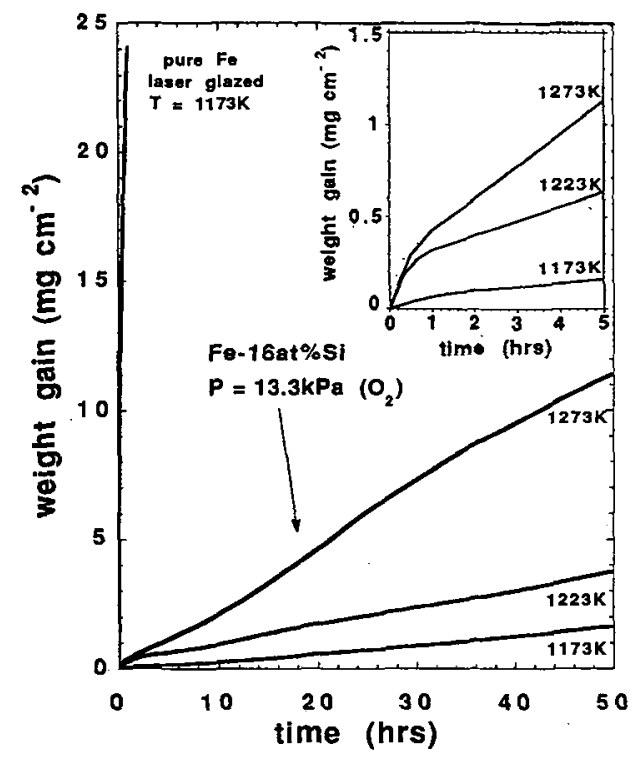

Fig. 5. - Oxidation kinetic curves of Fe-16 at\% Si alloy oxidized at temperatures between 1173-1273 K under an oxygen pressure of $13.3 \mathrm{kPa}$.

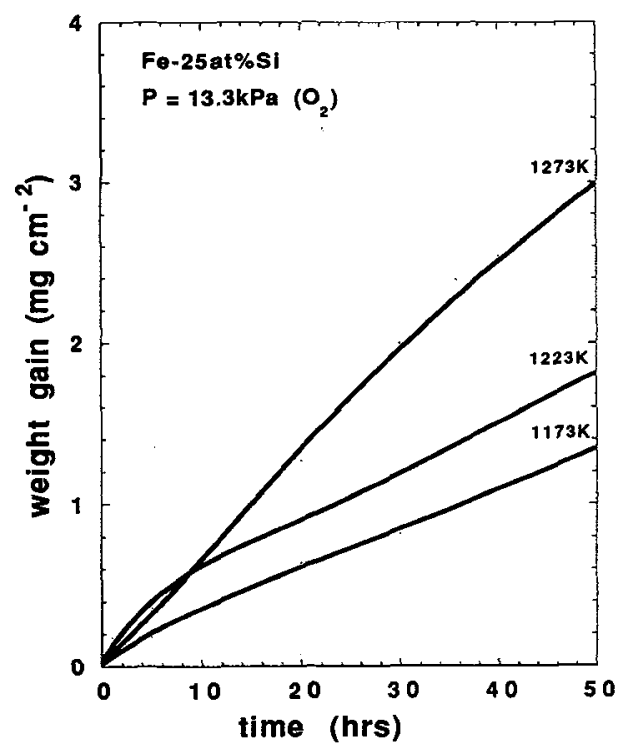

Fig. 6. - Oxidation kinetic curves of Fe-25 at\% Si alloy oxidized at temperatures between 1173-1273 K under an oxygen pressure of $13.3 \mathrm{kPa}$.

systems described it to be amorphous, while others $[5,6,19]$ observed it to be amorphous at the initial stage of oxidation, and on thickening, crystallized to $\beta$-crystobalite and ultimately 


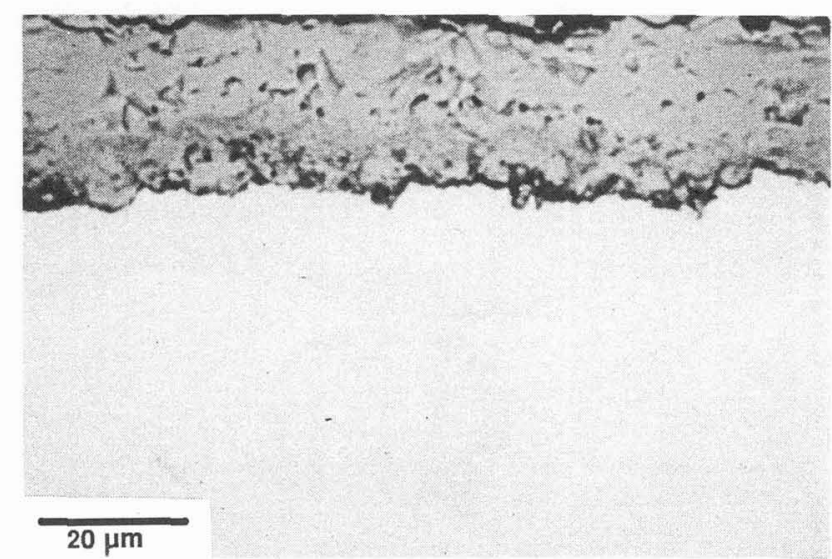

Fig. 7. - SEM (BEI) micrograph of the cross-section of the oxide scale formed on Fe-16 at\% Si alloy oxidized at $1273 \mathrm{~K}$ for 50 hours.

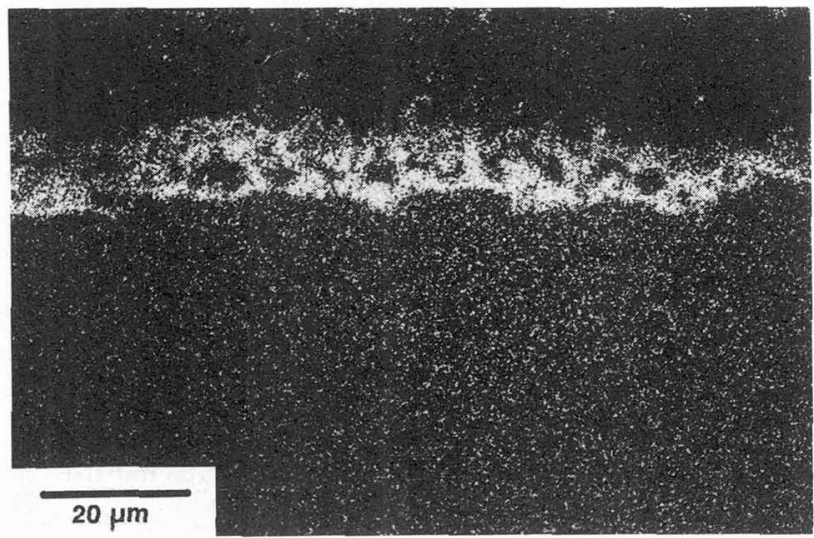

Fig. 8. - X-ray mapping of silicon in the oxide scale.

transforming to tridymite, which is the most stable form. Since XRD analyses done on the alloys failed to detect the $\mathrm{SiO}_{2}$ phase, it could be said that the $\mathrm{SiO}_{2}$ formed was amorphous. Whether it is amorphous or crystallized form of $\mathrm{SiO}_{2}$ appears to be of secondary importance since significant transport of a metallic element through $\mathrm{SiO}_{2}$ having an oxide less stable than $\mathrm{SiO}_{2}$ had been reported during oxidation of $\mathrm{Cu}-\mathrm{Si}$ [20], Ni-Si [15] and Fe-Si [5] alloys.

The development of the oxide scales on the two alloys occured by the same mechanism i.e., due to their high silicon content, both of them initially formed a discontinuous layer of $\mathrm{SiO}_{2}$. This layer was unable to prevent the inward penetration of oxygen and the outward diffusion of iron. As a consequence, the initial parabolic characteristic was observed. The oxygen diffused to the alloy beneath and reacted further to form more $\mathrm{SiO}_{2}$ while iron in its process 


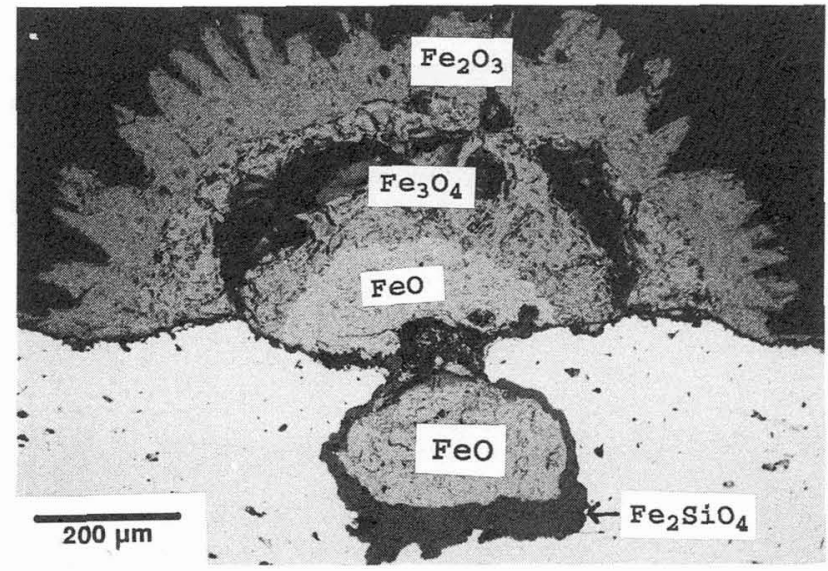

Fig. 9. - SEM (BEI) micrograph showing the cross-section of a nodule.

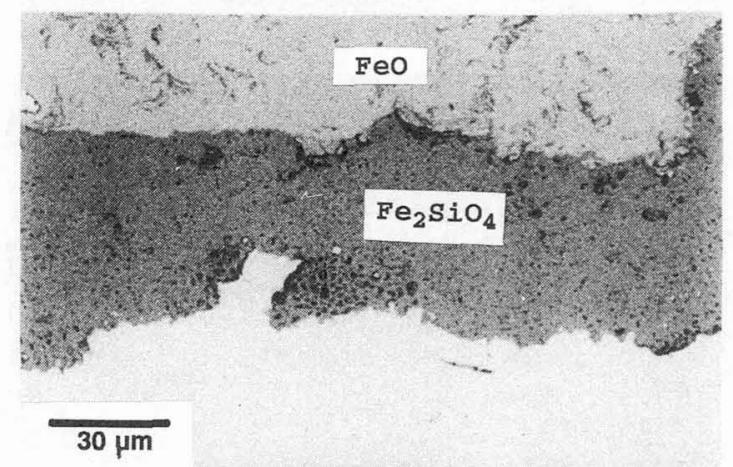

Fig. 10. - Enlarged view of $\mathrm{Fe}_{2} \mathrm{SiO}_{4}$ under $\mathrm{SEM}$ showing its porous nature.

of outward diffusion, reacted with the oxygen available around the discontinuous $\mathrm{SiO}_{2}$ layer to form a mixture of $\mathrm{SiO}_{2}$ and $\mathrm{Fe}_{2} \mathrm{O}_{3}$. With the passage of time, a smoother continuous healing layer of $\mathrm{SiO}_{2}$ was established and maintained at the base of the $\mathrm{SiO}_{2}$ and $\mathrm{Fe}_{2} \mathrm{O}_{3}$ mixture in contact with the alloy. With further exposure, only $\mathrm{Fe}_{2} \mathrm{O}_{3}$ was formed at the scale/gas interface due to the outward diffusion of iron. This outward diffusion of iron, which is probably in the metallic form through $\mathrm{SiO}_{2}$ [5] may have taken place across a constant thickness of $\mathrm{SiO}_{2}$ resulting in the linear oxidation kinetics observed.

The formation of nodules had earlier been attributed to the depletion in silicon concentration (at the internal oxidized scale boundary) to a value below which an effective $\mathrm{SiO}_{2}$ layer could form [2]. SEM micrograph of the cross section of a nodule formed on Fe-16 at $\%$ Si alloy is presented in figure 9. The outer shell of the nodule is found to consist of pure $\mathrm{Fe}_{2} \mathrm{O}_{3}$ with porous interior containing $\mathrm{Fe}_{3} \mathrm{O}_{4}, \mathrm{FeO}$ and $\mathrm{Fe}_{2} \mathrm{SiO}_{4}$ in sequence. An enlarged SEM view of $\mathrm{Fe}_{2} \mathrm{SiO}_{4}$ at the nodule base in contact with the surface alloy as depicted in figure 10 showed it to be highly porous which explains the chemistry of the nodule formation. However, the 
sites of nucleation for such localized manifestation of iron oxidation are possibly limited to the regions where surface cracks developed during oxidation. This idea is supplemented by the fact that the concentration of silicon in the alloy around the nodule base did not fall below an average value of 6 at\% and no internal oxidation as observed even after 140 hours of oxidation.

\section{Conclusion.}

Two Fe-Si surface alloy coatings have been prepared by laser irradiation on iron substrates precoated with silicon. The coatings were well adherent, defect free, compositionally and microstructurally homogeneous. They exhibited three to four times more surface hardness than pure iron as well as resistance to high temperature oxidation comparable to those of bulk Fe-Si alloys. Both of these properties increased with increasing silicon content. The reduction in oxidation rate is attributed to the presence of an amorphous $\mathrm{SiO}_{2}$ layer at the alloy/oxide interface which serves as a partial barrier to the outward diffusion of iron. Even though silicon had suffered inward diffusion into the substrate during oxidation, its concentration at the alloy/scale base did not fall below 6 at $\%$.

\section{References}

[1] Tuck C.W., Corros. Sci. 5 (1965) 631.

[2] Logani R.C., Smeltzer W.W., Oxid. Met. 1 (1969) 3; 3 (1971) 15 3, 279.

[3] Svedung I.; Vannerberg N.G., Corros. Sci. 14 (1974) 391.

[4] Moseley P.T., Tappin G., Riviere J.C., Corros. Sci. 22 (1982) 69.

[5] Adachi T., Meier G.H., Oxid. Met. 27 (1987) 347.

[6] Corkum J.L., Smeltzer W.W., Oxidation of High Temperature Intermetallics, T. Grobstein, J. Doychak Eds. (The Minerals, Metals and Materials Society, 1989) p. 97.

[7] SChnaAs A., GRabKe H.J., Oxid. Met. 12 (1978) 387.

[8] Fontana M.G., Greene N.D., Corrosion Engineering (Mc-Graw Hill, N.Y., 1978).

[9] Abba A., Galerie A., Caillet M., Mater. Chem. 5 (1980) 147.

[10] Kabbaj A., Galerie A., Caillet M., J. Less. Common. Met. 108 (1985) 1.

[11] Fasasi A., Pons M., Galerie A., J. Phys. (1992) in print.

[12] Galerie A., Fasasi A., Pons M., Caillet M., Surf. Modif. Technol. V (1992) in print.

[13] Pons M., Hugon A., Galerie A., Fasasi A., Sugier A., Surf. Coat. Technol. 45 (1991) 443.

[14] Fishman M.R., ZaHAVi J., Zevin L.S., J. Mater. Res. 3 (1988) 1108.

[15] STOTT F.H., Gabriel G.J., WOOd G.C., Oxid. Met. 28 (1987) 329.

[16] Tomkinson W.J., YATES J., Corros. Sci. 18 (1978) 823.

[17] Asнby M.F., SмITH G.C., J. Inst. Met. 81 (1952) 229.

[18] LOWELl C.E., Oxid. Met. 7 (1973) 95.

[19] BogGS W.E., Oxid. Met. 10 (1976) 277.

[20] Kapteijn J., Couperus S.A., Meijering J.L., Acta Metall. 17 (1969) 1311. 